\title{
Integrating Implicit and Explicit Emotional Assessment of Food Quality and Safety Concerns
}

\author{
Alexandra M. Walsh ${ }^{a}$, Susan E. Duncan ${ }^{a}$, Martha Ann Bell ${ }^{\text {b }, ~ S . ~ F . ~ O ' K e e f e ~}{ }^{\text {a }}$, and Daniel L. \\ Gallagher $^{\mathrm{c}}$
}

${ }^{a}$ Department of Food Science and Technology, Virginia Polytechnic Institute and State

University (Virginia Tech), Blacksburg 24061, USA

${ }^{\mathrm{b}}$ Psychology Department, Virginia Tech, Blacksburg 24061, USA

${ }^{c}$ Department of Civil and Environmental Engineering, Virginia Tech, Blacksburg 24061, USA

Corresponding Author:

Susan E. Duncan, Ph.D., R.D.

104C Hutcheson Hall

250 Drillfield Dr.

Virginia Tech, Blacksburg 24061

Telephone: 540-231-3766; Fax: 540-231-9293

Email: duncans@vt.edu

(C) 2016. This manuscript version is made available under the Elsevier user license http://www.elsevier.com/open-access/userlicense/1.0/ 


\section{ABSTRACT}

Tools for automatic facial expression analysis (AFEA), frontal cortex (EEG) and cardiac electrical activity (ECG) may bring additional support to traditional sensory techniques for a better understanding of implicit physiological and emotional response to food. To enhance the understanding of consumer emotional response to food, participants (age: 18-29 years; $\mathrm{n}=40$, female $=31$ ) were presented with videos (average $40 \mathrm{sec}$ ) of food concerns (safety, hygiene and spoilage; called evented videos) and matched control (no food concern; called control videos) videos, while implicit emotional responses (AFEA, EEG and ECG) and expressed explicit emotional responses were measured concurrently. AFEA analyzed facial expressions for the six basic emotions $(0=$ not expressed; $1=$ expressed $)$; EEG measured frontal cortex asymmetry for motivational behavior tendency (right hemisphere activation = withdrawal: scared, sad and disgust; left hemisphere activation = approach: happy, surprised and angry; 10/20 system, 32 channels, $512 \mathrm{~Hz}$ ), while ECG measured heart rate (bpm) changes. Explicit emotions were assessed using a list of emotional terms $(n=43)$ in a check-all-that-apply method and acceptability was rated on a 7-point hedonic scale (1=dislike extremely; 7=like extremely). Withdrawal emotions, disgust and worried, were significantly chosen more for evented videos, while approach emotions (content, good, good-natured, interested, pleasant, pleased and satisfied) were significant for all control videos $(\mathrm{p}<0.05)$. Acceptability scores were significantly lower $(\mathrm{p}<0.05)$ for the evented meals. Significant differences in heart rate may indicate emotional response. AFEA results for quality (spoilage, hygiene) concerns found greater variety of emotion expression compared to the safety concern, while frontal cortex asymmetries were inconsistent. More research is needed to validate the use of implicit measures (EEG, ECG and AFEA) in providing information for understanding differences in emotional response to food 
safety, hygiene and spoilage events. The evaluation of displeasing or unpleasant characteristics of food, through the integration of implicit and explicit responses, will lead to a greater understanding of the consumer-food relationship.

\section{KEYWORDS}

Emotion, EEG, ECG, facial expression, food quality, food safety, meal 


\section{INTRODUCTION}

Understanding the influence of negative emotional 'side effect' experiences by the consumer is as important as understanding positive responses in food product design (Desmet \& Hekkert, 2009). In many sectors of the food industry, including food service and retail establishments, this is essential for success. The idea of establishing consumer confidence in quality and safety is important for brand loyalty, satisfactory customer service, as well as for motivating customer return and purchasing behavior (Desmet \& Hekkert, 2009; Lassoued \& Hobbs, 2015). Increased interest in the consumer experience with food has inspired exploration of emotional influence on decision making and behaviors toward products and foods (Desmet \& Hekkert, 2009; Gutjar, de Graaf, Kooijman, de Wijk, Nys, ter Horst \& Jager, 2015). Kubberod, Ueland, Digstad, Risvik \& Henjesand (2008) emphasize the reduction of undesirable emotions, such as disgust, to ensure positive food-associated emotional experiences. Barriers to purchase and consumption can develop when implicit or direct associations are made between negative experiences, such as food advertisements that create adverse emotions, and a food item (Kubberod et al., 2008; Shimp and Stuart, 2004). Most research on emotions in food science literature focuses on the discriminating capabilities of foods that are positive perceived, such as indicated by high level of acceptance, using traditional explicit or written ballot methodologies (Jiang, King \& Prinyawiwatkul, 2014; King, Meiselman \& Carr, 2010). However, little attention has been given to understanding the attributes of food that may cause negative effects that influence consumer dissatisfaction, customer complaints, brand damage or declining or low sales activity (Kubberod et al., 2008; Shimp \& Stuart, 2004; Wardy, Sae-Eaw, Sriwattana, No, \& Prinyawiwatkul, 2015). Increased interdisciplinary engagement between psychology and food science and advancements in technology for measuring implicit emotional response are creating 
new approaches and a deeper understanding of the emotional and motivational behavior tendencies in connection to food. Implicit or non-verbal responses, such as facial expressions and brain activity, as well as physiological measures of heart activity, skin conductance and skin temperature are being explored for application to food science questions. Observing emotional responses and motivation behaviors to displeasing food experiences may be valuable in providing a more complete understanding of the relationship between the consumer and food. Understanding food attributes that have the potential for both lowering consumer acceptability and increasing implicit or direct association of negative emotions is important for product developers and other food professionals to understand (Wardy et al., 2015).

Assessment of emotional response to foods is a rapidly growing area of food science; how emotions affect responses to food acceptability, intent to purchase, food choice, attitudes and food behaviors are a few of the areas already studied (Jiang et al., 2014; Wardy et al., 2015). However, studies on emotional response to food hazards and concerns are limited. Wardy et al. (2015) found that unwholesome eggs, defined as eggs lacking a safety attribute, received significantly lower liking scores as well as lower 'safe' emotion selection and higher 'worried' and 'disgusted' term selection. It is hypothesized that the feeling of disgust originally developed to protect against unsafe or contaminated food demonstrating a bad taste (Rozin and Fallon, 1987; Rozin, 1996; Rozin, 1999; Rozin, 2007). Tastes recognized with disgust response are associated with illness and the feeling of nausea, separating its meaning from dislike or distaste to a food (Rozin, 1996). Additionally, Olsen, Rossvoll, Langsrud \& Scholderer (2014) determined that 'fear' and 'disgust' term usage safeguarded individuals against potential risky foods (e.g. undercooked hamburgers). Thus obstacles to purchasing and/or consumption of a food can be created not only from one's preference, but also when the feeling of disgust is 
associated with the product or brand (Kubberod et al., 2008). Specifically, foods from animal origins that have begun to decay or spoil or have been tainted by poor hygiene are all disgust elicitors.

The well-studied universal facial expression of disgust and other communication modalities (Rozin, 1996; Rozin and Fallon, 1987; Rozin 2007) include an upper lip raise, wrinkling of the nose, and the bottom lip lowering in a gaping fashion, which bear importance for communicating a revulsion or withdrawal response to a food (Rozin, 1996; Rozin and Fallon, 1987; Rozin 2007; Zeinstra, Koelen, Colindres, Kok, \& de Graaf, 2009). Wendin, Bredie \& Tan (2014) further suggest these communicative facial expressions are either a warning signal to others for a potential danger or designate a distaste response. Conversely, positive facial expressions serve as an affirmation for safe consumption or of sensory pleasure (Wendin et al., 2014). Facial expressions are not the only means of communication of disgust; Shimp \& Stuart (2004) found food advertisements of undercooked meat products elicited strong written disgust responses. Phrases such as "gross," "obnoxious," “... not appealing,” and “.. looked nasty" were all used to describe meat in the meal presented in the advertisement. These examples emphasize the importance of understanding all attributes of a food to reduce unintentional negative affect that could influence purchase intent (Shimp \& Stuart, 2004).

Both explicit written or oral responses and facial expressions provide valuable indications of emotion but are influenced by external factors. Measures of implicit response, such as heart and brain activity, to attributes of concern in food may provide additional cues related to emotions. Such information may provide clues to consumers' food preferences and behaviors, providing additional validation and support for interpreting facial expressions and explicit verbal emotional terms expressed. Explicit emotional response methods run the risk of being affected 
by cognitively determined factors (Jiang et al., 2014), which may affect validity of emotional assessment. Training for reliable and consistent manual coding of facial expressions is time intensive, requiring a minimum of 10-20 hr (Kring and Sloan, 2007). Validating inter-rater reliability and limiting rater drift requires recurring verification and training, as needed, for improvement (Kring and Sloan, 2007), thus reducing the ease of use in industry settings. Automated facial expression analysis (AFEA) software tools have been developed as an alternative to manual coding of facial expression.

AFEA software tools analyze the face for muscle movements of the lips, eyes, cheeks, mouth, etc. and translates the combinations of facial movements to classify and provide an estimate of intensity for the six basic emotions (Loijens \& Krips, 2012; Noldus Information Technology, 2012). AFEA has been used in a few food science studies (Arnade, 2013; Danner et al., 2013; Danner et al., 2014; de Wijk et al., 2012; de Wijk et al., 2014; He, Boesveldt, de Graaf, de Wijk, 2014; He, Boesveldt, de Graaf, de Wijk, 2016; García Burgos, D., \& Zamora, M.C., 2013; Garcia Burgos, D., \& Zamora, M.C., 2015; Leitch, Duncan, O’Keefe, Rudd, \& Gallagher, 2015; Walsh, Duncan, Potts, \& Gallagher, 2015; Crist, Duncan, Gallagher, 2016). In these studies (with the exception of: García Burgos, D., \& Zamora, M.C., 2013; Garcia Burgos, D., \& Zamora, M.C., 2015), the general approach was to determine if product acceptibility differences could be detected through facial expression analysis. Danner et al. (2014) and He et al. (2016) found neutral expressions to be more greatly associated with "liked" or "positively valanced" samples. Leitch et al. (2015) reported significant variation in responses among participants tasting sweetened teas. In general, there is literature evidence that disliked foods are more readily identifiable by discrete expression of disgust, whereas differentiating among liked foods based on discrete neutral and positive expressions is not readily accomplished (Zeinstra et 
al., 2009). Leitch et al. (2015) did note differences in the temporal relationship of emotions in teas sweetened with different sweeteners using a time series analysis method. Crist et al. (2016) further described the measurement of temporal effects on emotions in milk with acceptability scores in the 'liked slightly' range, illustrating differentiation of products based on emotional expression and timing. Products that were more less liked were also differentiated based on this method. However, deepening the understanding of expressed emotional responses to negativelyvalanced or food experiences that elicit withdrawal responses would be a logical step. Such knowledge may be applied to reducing unwanted negative responses, ultimately leading to greater consumer satisfaction. In our search of published literature, we found no AFEA studies focused on understanding emotional withdrawal aspects related to common food quality and safety experiences.

Physiological measures, especially cardiac responses, are another emerging method for providing additional information about emotion processing associated with food. In a review article by Kreibig (2010), cardiac electrical activity, measured as heart rate (HR), is described as being both emotion specific as well as more broad and non-specific; HR response also is highly variable among individuals within a population. Emotion-specific literature suggests that happiness, joy, disgust (contamination), surprise and others, typically manifest as an increase in HR, while sadness (non-crying or acute), contempt (visual), anticipatory pleasure and others, to cause a decrease in HR (Kreibig, 2010). Fernandez, Pascual, Soler, Elices, Portella, \& Fernandez-Abascal, (2012) show cardiac responses as well as other autonamic nervous system (ANS) measurements can be used to measure arousal or used with dimensional (positive/negative or pleasant/unpleasant) differences when the context is known (Kreibig, 2010). In the limited food science studies relating HR to food experiences, HR findings are 
inconsistent; the literature is similar to AFEA studies in that they relate HR to acceptability for product development questions. de Wijk et al. (2014) found that liking was positively related to higher HR when tasting breakfast drinks; however a study on food odors found that liked smells resulted in a decrease in HR (He et al., 2014). Conversely, in an earlier study by de Wijk et al. (2012), they reported a trend for higher HR to disliked foods, whereas other researchers saw no significant correlation between cardiac responses (or other ANS measures) and liking (Danner et al., 2014). Further research is needed for understanding HR and emotional responses to food (Danner et al., 2014) .

Another physiological method, electroencephalography (EEG), measures the electrical potential between two electrodes on the scalp, with evidence that the origin of this electrical signal is in the brain (Pizzagalli, 2007). The EEG signal is spontaneous but context-related; thus the EEG signal from an individual during quiet rest differs quantitatively from the signal generated when someone is processing various cognition- or emotion-based stimuli. EEG reflects postsynaptic potentials of the brain's neurons and these electrical changes are reflected in the EEG recorded at the scalp within milliseconds, making this methodology outstanding for tracking rapid shifts in brain functioning (Bell \& Cuevas, 2012). For emotion processing, the frontal cortex area is of particular focus (Coan \& Allen, 2003; Coan \& Allen, 2004; Davidson et al., 1990; Diaz \& Bell, 2012). Activation of the right hemisphere of the frontal cortex, has been associated with withdrawal motivational tendencies or a tendency to move away from the stimuli, while the left hemisphere is associated with approach motivational tendencies or a tendency to move toward the stimuli (Alves et al., 2008; Coan \& Allen, 2003; Coan \& Allen, 2004; Davidson et al., 1990; Davidson, 2004; Davidson \& Irwin, 1999; Diaz \& Bell, 2012; Harmon-Jones, Gable, \& Peterson, 2010). Psychology literature contains a broad scope of 
research measuring brain activity and emotional response to food. However, the attention of these studies are most often targeted towards food behaviors and motivations in disordered eating or dieting populations, as related to food temptations, craved foods, reward/punishment feelings and goal pursuits (Berkman \& Lieberman, 2009; Giuliani, Mann, Tomiyama \& Berkman, 2014; Siep, Roefs, Roebroeck, Havermans, Bonte, \& Jansen, 2012; Silva, Pizzagalli, Larson, Jackson, \& Davidson, 2002). With the exceptation of one study by Silva et al. (2002), who studied normal and restrained eating populations' responses to food, measuring approach/withdrawal tendencies using frontal asymmetries from EEG data in response to food quality, safety, and innovation questions is not well researched. No studies have been completed using EEG to measure frontal cortex asymmetry responses in a general normal eating population as a tool for measuring aversive attributes to food for a greater understanding of emotional and motivational responses in food experiences. Brain activity is part of the larger complexity of the emotional and motivational behavior response systems; therefore, its incorporation with other implicit and explicit emotional responses provides a more complete and dynamic image of the relationship between emotion and food.

In order to better understand the consumer-food relationship, this study compared responses to positive and negatively-valanced food experiences, using multiple implicit and explicit measures of emotion and behavior motivations. Withdrawal-eliciting stimuli included foods containing off-putting quality (spoilage and hygiene) and safety characteristics. The goal of this study was to simultaneously capture multiple implicit and explicit response measures for a more complete assessment and interpretation of emotional and motivational behaviors to foods and food concerns. 
In the assessment of emotional and motivational behavior measures of food concerns, we hypothesize:

\section{A. Explicit measures:}

1. Hedonic ratings for food concerning stimuli (evented) will be lower than the (matched) control stimuli.

2. Withdrawal (negatively valanced) emotions will be more prevalent for the evented stimuli and approach (positively valanced) emotions will be more prevalent for control stimuli.

\section{B. Implicit measures:}

1. AFEA will show greater withdrawal emotional expressions for the evented stimuli post-event occurrence, compared to a neutral/positive emotional expression for the control stimuli post-event occurrence. Pre-event AFEA for both the evented and control stimuli will be neutral (or positive).

2. ECG analysis will support AFEA and show differences in HR (bpm) to illustrate emotion specificity (disgust, happy and surprise - increase HR; sad decrease HR). No difference in HR will be observed prior to event occurrence between control and evented stimuli.

3. EEG analysis will determine an approach or withdrawal motivational behavior tendency through frontal cortex asymmetries; evented stimuli will have a greater withdrawal response (right hemisphere activation), and control stimuli will have a greater approach response (left hemisphere activation). No difference in frontal asymmetry scores will be observed prior to event occurrence between control and evented stimuli. 


\section{MATERIALS AND METHODS}

\subsection{Participants}

Institutional Review Board (Blacksburg, Virginia) approval was obtained prior to human testing began (IRB Approval \#: 14-020). The Psychology department's SONA Experimental Management System at Virginia Tech was used to recruit students who were seeking extra credit. Informed consent was obtained for the forty students who participated (18-29 years; female=31). Exclusion criteria included excessive facial hair, eyeglasses, contact lenses, and left handedness. The former two were exclusion criteria because of potential interference with AFEA. The latter two were exclusion criteria specific to the EEG recordings. Contact lens wearers tend to have a higher blink rate, which interferes with the amount of usable EEG data. Right-handed participants are typical for EEG studies because cortical hemispheric specialization is different for left-handed individuals. Lastly in order to help reduce learned biases, Food Science and Technology, Human Nutrition Foods and Exercise, and other related majors were excluded from participation.

\subsection{Video Stimuli: Food Hygiene, Safety, and Spoilage}

Eight color videos averaging 40 seconds in length were recorded using a Sony PMWEX1R high definition video camera (Sony Corporation, MinatoFpa, Tokyo). No sound was recorded. Three breakfast meal videos containing emotion-eliciting events ("evented" with food hygiene, safety, and spoilage concerns) were matched with their nearly identical control (no concern) videos making three sets of two videos (Table 1). Videos were chosen as stimuli (in contrast to pictures or freshly prepared food products) in order to reproduce a dynamic situation, while providing standardization across participants and the ability for replication of results (Fernandez et al., 2012). Real food was not used in order to control for participant movements 
associated with consumption, as well as control for other sensory characteristics (smell) that could influence results if not uniform across all participants. The category of breakfast meals was chosen for the variety of meal types that offered apparent food concerns, while providing some cohesion to the types of food presented. Two additional unmatched video meals (without a food concern) were also developed in order to distract the participant from learning the matched pattern of videos.

Food video preparation was completed in a neutral dining setting. A neutral white wall served as the back drop with a table as the central surface. A maroon table cloth, white or clear dishes and basic silver utensils were used as a common setting for all videos. Each video began with an empty plate/bowl and/or utensil in place. Hands for preparing the meal were included as minimally as possible. Once the meal was prepared and to simulate consumption, the food was carried (bite-size) on an eating utensil to the front of the screen toward the participant. The camera was placed at a distance with the angle positioned as if the viewer was seated at the table.

An additional non-food (beach scene) video was used to induce a calming effect in an effort to return the participant's emotional state back to baseline between food videos. A short description of the videos follows (Table 1).

\subsection{Emotional Measures}

Two different emotional response types were recorded: implicit and explicit. Implicit responses, for this study, are defined as responses that are not verbalized or written by the participant. Brain activity and HR are considered implicit because they are not cognitively determined; they are physiological reactions. Facial expressions, although they can be cognitively controlled, have been grouped into the implicit results because facial responses are 
not a written or verbal response. Explicit responses are defined as written (or verbal) responses that have been subject to thought and/or reason and can be recorded through questionnaires. All measures were completed in a laboratory housed within the Psychology Department.

\subsubsection{Implicit Measures: EEG, ECG and AFEA}

Brain activity was measured using electroencephalography (EEG). Collection was completed continuously throughout the research visit using Snapshot-SnapStream (HEM Data Corp.; Southfield, MI) and Instrumentation Bioamps (San Diego, CA) systems. Electrical response was recorded at $512 \mathrm{~Hz}$. The high pass filter was $0.1 \mathrm{~Hz}$ and the low pass filter $100 \mathrm{~Hz}$ with a gain of $5,000 \mathrm{~Hz}$. The location of the electrodes followed a 10/20 system and 32 EEG channels were collected, using a midline reference $(\mathrm{Cz})$ and a scalp ground reference anterior to the Fz electrode. Omni-Prep abrasive gel was first applied to the scalp at each electrode with a blunt syringe for preparation of the scalp. Then a conductive gel, Electro-Gel, was applied. Electrode impedances were under $5 \mathrm{~K}$ ohms to ensure a high quality recording. An acquisition computer displayed and stored raw data for subsequent analysis. The alpha bandwidth was used to detect brain activity at a frequency of 8-to-13 Hz (Ahern \& Schwartz 1985; Coan \& Allen, 2004).

HR activity was measured using electrocardiography (ECG). By placing two disposable electrodes on the participant, one on the lower left rib and the other on the right collar bone, cardiac electrical impulses were measured. The ground electrode was anterior to Fz on the scalp. To amplify the electrical activity, the SA Instrumentation Bioamp was used with a bandpass filter set at $0.01-1000 \mathrm{~Hz}$. The same acquisition computer that displayed the EEG also displayed the ECG data. The ECG signal was recorded at $512 \mathrm{~Hz}$. The Snapshot-Snapstream 
(HEM Data Corp., Southfield, MI) was used to record and store the raw data. Cardiac electrical activity was recorded throughout the testing.

A discrete video camera (Panasonic North America, Newark, NJ) was located above the TV monitor used for participant viewing of the breakfast meal videos. The zoom and toggle features, managed by the technician, allowed the camera to be adjusted squarely and tightly on each participant's face. Video recordings were taken to be later evaluated with AFEA software (FaceReader 6.0, Noldus Information Technology, Wageningen, The Netherlands).

\subsubsection{Explicit Measures}

Two different questionnaires were used to collect explicit responses to the breakfast meal videos. Acceptability was rated on a 7-point hedonic scale scorecard (1= "dislike extremely," $4=$ “neither like nor dislike," 7= "like extremely"). A Check-All-That-Apply (CATA) emotional terminology selection questionnaire (EsSense ${ }^{\mathrm{TM}}$ Profile; King \& Meiselman, 2010), was modified to a list of 42 terms, as described by Arnade (2013). Three additional emotion terms (angry, fearful and sad) were added to compare this explicit response to AFEA responses as well as include all six basic emotions. 'Safe' was also added because the study was designed to evaluate food concerns that may affect one's sense of security and acceptability of the meal presented (Arnade, 2013; Arnade et al., 2013; Olsen et al., 2014). Additionally, 'glad' was removed from the list due to its similarity in meaning to happy (Arnade, 2013; Arnade et al., 2013; Ekman et al., 1987). In addition, a rating scorecard to assess perceived intensity of the six basic emotions ( $1=$ not at all; $7=$ extremely) was completed. These three affective questionnaires were completed after watching each food video. Following all stimuli, an additional questionnaire was given to assess food preferences about the specific types of breakfast meals presented. 


\subsection{Overview of Design}

\subsubsection{Test Conditions}

Upon scheduling a two-hour appointment and obtaining informed consent, the EEG and ECG set-up and electrode application began, taking about 30 mins for each participant. The two ECG electrodes leads were placed first, followed by the EEG cap. Capping and machine calibration was accomplished by the trained lab technician. During this preparation, the participants were instructed to fill out a demographics questionnaire as well as to familiarize themselves with the three explicit emotional response questionnaires. They were directed to sit facing the video screen and minimize movements to ensure quality video, ECG and EEG recordings. A technician controlled the equipment from the adjacent room, as well as marked previously determined "emotion eliciting events" (safety, hygiene and spoilage concerns) in each "evented" video and corresponding "non-emotion eliciting events," in the "control" videos for reference during the analysis phase. Each participant's session began with baseline EEG/ECG recordings; participants were asked to sit quietly for two minutes with their eyes open and two minutes with eyes closed (Coan \& Allen, 2003). A moderator quietly sat at the back of the room and controlled the television monitor with the video presentations. The moderator allowed the participant to fill out the scorecards at their own pace following each of the nine videos. The control video always preceded the evented video to minimize repulsion from the food concern presented. The beach scene video was shown directly before each separate video in order to reduce carry over of emotions and to help minimize potential anticipatory effects. The unmatched distractor videos were inserted between matched video sets. An example schematic of a set of videos is presented below (Figure 1). Additionally, due to researcher perception that the undercooked meat (sausage sandwich video) was the least obvious issue in internal beta 
testing, it was always presented last. The other videos were presented in a balanced manner. Following completion of all videos and emotion scorecards, the final questionnaire on food preference was given and each participant was aided with the removal of the EEG cap and ECG electrodes.

\subsection{Data Analysis/ Statistical Technique}

\subsubsection{Data Analysis for Implicit Responses: EEG, ECG and AFEA}

ECG data was analyzed using IBI Analysis System software (James Long Company, Caroga Lake, NY). First, segments associated with movement-related artifact were removed. Once edited, artifact-free R waves were converted into interbeat intervals (IBIs) and further converted into equal $125 \mathrm{~ms}$ time intervals and beats per minute (bpm) was calculated. Event times manually marked during each session served as a point to split each video into two segments: "pre-event" and "post-event". Because emotions are believed to last anywhere between 0.5 - 4 seconds (de Wijk et al., 2014; Fox, Kirwan \& Reeb-Sutherland, 2012; Leitch et al., 2015; Scherer, 2008), we chose five seconds prior to the event (safety, hygiene and spoilage) occurrence and five seconds following in order to capture all emotion around the event. Independence, normality and equal variance were validated for ECG data. Pairing was completed within participant. The mean HR (M) (bpm; $n=40)$ and standard deviations (SD) for the pre- and post- event five second segments were found for each participant ( $n=40$; Excel 2013, Microsoft Corporation, Inc., Redmond, WA). Then paired Student's t-tests $(\alpha=0.05)$ were calculated for both the pre- and post- event time segments; comparisons were completed between the control and evented videos. 
Collected brain activity data was analyzed using EEG Analysis Software (James Long Company; Caroga Lake, NY). First, segments associated with eye bink and gross motor artifacts were removed. Then EEG data were analyzed with a discrete Fourier transform (DFT) with a $50 \%$ overlap and a Hanning window of 1-s width. The data were transformed with a natural log to normalize the distribution for data analysis, as per standard EEG procedures. The mean EEG value for each electrode was found for the same pre- and post- event five second segments as the HR analyses for each participant. Validation of independence, normality and equal variance were tested. Pairing was completed within participant. To find individual frontal cortex asymmetry score, the mean value of the F3 electrode measuring the left hemisphere was subtracted from the mean value of the F4 electrode measuring the right hemisphere for the same five second duration (right - left $=$ frontal asymmetry; Coan \& Allen, 2004). Paired Student's ttests $(\alpha=0.05)$ of the average asymmetry difference for both pre- and post- event time segments were compared between the control and evented videos.

Prior to AFEA, video recordings were edited (Final Cut Pro X, Apple, California) to remove extraneous footage $(\mathrm{n}=40)$. Edited videos were analyzed using the individual calibration setting within the AFEA software (FaceReader 6.0, Noldus Information Technology, Wageningen, The Netherlands) at approximately 30 frames per second. Footage of each participant during the baseline ECG and EEG recordings (eyes open) were used to create individual calibrations (two seconds); no stimuli were present and the participants were in a relaxed state (Danner et al., 2013; Danner et al., 2014). Events were manually marked within the software program and automatically analyzed facial recognition data was exported as text files for further analysis. Text files contained means of intensity $(0=$ not expressed; $1=$ expressed $)$ of the six basic emotions (anger, happy, disgusted, sad, scared and surprised) for each video 
presentation. Two separate analyses were performed: 1) mean emotion expression intensity (5 sec) comparison between and within emotion using a two-way analysis of variance (ANOVA) and Tukey’s HSD test for significance (JMP Statistical Analysis Software (SAS) Version 9.2, SAS Institute, Cary, NC), and 2) time series analysis for significant differences in occurrence of emotion expression over time (R, version 3.1.1; R Core Team, 2013; Crist et al., 2016). The second method evaluated the responses for 20 seconds (10 seconds pre- and 10 seconds postevent). Previous studies evaluated responses post five seconds of event occurrence (Leitch et al., 2015; Crist et al., 2016); however de Wijk, et al. (2014) found different emotions initiate at different times and have varying durations. Due to our stimuli being a video, the duration of ten seconds after the emotional event was chosen to provide sufficient time for emotional development on the face. Shapiro Wilks tests identified that the time series data were not normally distributed. Sequential paired nonparametric Wilcoxon tests (R, version 3.1.1; R Core Team, 2013) were performed between the control and the corresponding treatment at each video frame (Crist et al., 2016) to identify significant positive and negative emotional differences over time $(20 \mathrm{sec})(\alpha=0.025$ for positive and for negative differences; $n=40)$. Results were summarized and plotted into dot diagrams which illustrate where significant differences in emotion expression intensity exist between the matched control and evented breakfast meals within $20 \mathrm{sec}$.

\subsubsection{Data Analysis for Explicit Responses: Acceptability, Emotion Term Selection and Food}

\section{Preference Questionnaires}

Explicit responses included acceptability scores and CATA emotional terminology

selection (EsSense ${ }^{\mathrm{TM}}$ Profile; King \& Meiselman, 2010). Demographic and food preference 
questionnaires also were collected and were tabulated in an electronic spreadsheet (Excel 2013, Microsoft Corporation, Inc., Redmond, WA).

For each stimuli, normality of acceptability scores was determined using the ShapiroWilk Goodness-of-Fit test (JMP Statistical Analysis Software (SAS) Version 9.2, SAS Institute, Cary, NC). A comparison of mean hedonic scores using Tukey-Kramer test (JMP Statistical Analysis Software (SAS) Version 9.2, SAS Institute, Cary, NC) determined the significance $(\alpha=$ 0.05) between control and evented videos. A one-way analysis of variance (ANOVA) test (JMP Statistical Analysis Software (SAS) Version 9.2, SAS Institute, Cary, NC) was completed to determine confidence intervals and median hedonic scores for all pairs $(\alpha=0.05)$.

CATA emotion terminology categorization was based on frequency of selection of emotion terms. Terms that failed to be chosen greater than or equal to $20 \%$ for at least one breakfast meal were removed from further analysis (Arnade, 2013; Arnade et al., 2013; King \& Meisleman, 2010). Spider graphs present the percent frequency of choice for these frequently selected emotional terms. Multiple Cochran's Q tests were completed for frequently selected terms to determine their significance across all videos (XLSTAT, 2015, Addisonsoft, New York, NY).

\section{RESULTS}

\subsection{Explicit Response Results}

The control videos always received a greater mean acceptability than the evented videos $(\alpha=0.05$; Figure 2). The control pancake and fruit breakfast meal was "liked moderately" and received the highest average score $(\mathrm{p}<0.05 ; 5.8 \pm 1.34)$. The evented pancake and fruit breakfast meal (hygiene) video was "slightly disliked" and received a significantly lower score ( $<<0.05 ; 3.4 \pm 1.72$; Table 2$)$. The control cereal and milk breakfast meal was "liked slightly" 
and the evented stimuli (spoilage) was "disliked moderately," receiving significantly different mean scores $(\mathrm{p}<0.05 ; 4.7 \pm 1.24 ; 2.0 \pm 1.15)$. The sausage sandwich breakfast meal received the lowest acceptability overall; the control was "neither liked nor disliked," and was a significantly higher score than the "disliked extremely" evented (safety) video ( $\mathrm{p}<0.05 ; 3.8 \pm$ $1.73 ; 1.8 \pm 1.30)$.

Nine terms were chosen less than $20 \%$ of the time for all videos (including the beach scene) and were removed from further analysis: affectionate, aggressive, daring, energetic, guilty, merry, polite, tame and wild. Ten additional terms were removed from analysis due to their infrequency of usage in food only comparisons (adventurous, free, loving, mild, nostalgic, quiet, secure, safe, steady and tender). Evented meals received very high disgust responses; over $80 \%$ of the population chose disgust for all of the evented videos (Figure 3).

Based on a Cochran's Q analysis (XLSTAT, 2015, Addisonsoft, New York, NY), all three control videos were significantly similar in choice for approach emotions: content, good, good-natured, interested, pleasant, pleased and satisfied $(\alpha=0.05)$. Two withdrawal emotions were significantly chosen for all three evented videos: worried and disgusted $(\alpha=0.05)$. Worried was used frequently for the control sausage sandwich breakfast meal video (20\% relative frequency) and was not different in relative frequency $(p>0.05)$ to the evented pancakes and fruit breakfast meal (hygiene (27.5\%); control pancakes and fruit (5\%), and cereal and milk $(0 \%))$. For disgust, the control safety video received a $45 \%$ relative frequency, not different from ( $p>0.05)$ to the evented pancakes and fruit meal (hygiene $(80 \%)$; control pancakes and fruit $(12.5 \%)$ and cereal and milk (7.5\%)). The evented spoilage and safety videos both received $95 \%$ term usage for disgust (not different $(\mathrm{p}>0.05)$ in usage to the evented hygiene video $(80 \%)$ ). 


\subsection{Implicit Response Results}

Mean intensities of emotions, expressed over five seconds pre- and post- event occurrence for both the control and the evented videos, were completed (Tables 3 and 4). Within emotion and across stimuli, no significant differences in expressed emotional intensity were found for either the pre- or post- event analysis ( $p>0.05$ ). Differences are seen within stimuli and across emotions. Pre-event and post-event analysis indicate neutral as uniquely more intense in expression for the five second duration for all videos ( $\mathrm{p}<0.05$ ), and anger (not unique) received the second highest intensity scores $(\mathrm{p}<0.05)$. All other expressed emotion intensities were different across emotions and within food stimuli.

In AFEA time series graphs (Figure 4, a-c) time zero indicates when the event occurred and ten seconds pre-event and ten seconds post-event were analyzed. The moment the event occurs is specific to each video, but comparable in the progression of the meal preparation across all videos. Each dot on the graph represents when the corresponding video frame generated a statistically significant stronger emotion across participants for the evented video (upper portion of the graph) or for the control video (lower portion of the graph). The absence of a dot indicates no statistical difference for that time. This type of presentation allows for many individual time series to be combined and summarized in one figure. These dot graphs are not illustrating the intensity value of the emotion expressed, but the presence (or absence) of an emotion expression intensity that is statistically significantly different in one treatment video compared to the matched control based on sequential paired nonparametric Wilcoxon tests. As discussed below, time series graphs show a wide range of facial expressions displayed between the different meal types. 
HR data were analyzed between sets of evented and control stimuli for both the pre- and post- event occurrence (Table 5). As expected, no differences were found in mean five second HR prior to the stimuli ( $n=40, p>0.05)$. Post-event comparisons saw significant differences in HR ( $<<0.05)$; evented hygiene concern $(\mathrm{p}=0.041)$ and safety concern $(\mathrm{p}=0.017)$ videos had a statistically significant increase in $\mathrm{HR}(\mathrm{t}=2.111, \mathrm{t}=2.484$; respectively). Conversely, the postevent comparison for the evented spoilage concern $(\mathrm{p}=0.018)$ video had a statistically significant decrease in HR ( $\mathrm{t}=-2.481)$ compared to the control.

EEG analysis of motivational behavior response focused on frontal cortex asymmetry score for the F3/F4 electrodes. P-values (Table 6) show if differences in mean response between control and evented videos occur, while the t-statistics show direction. A negative t-statistic (negative asymmetry score) indicates greater relative activation of the F4 electrode (right hemisphere of the frontal cortex) compared to the F3 electrode (left hemisphere). A positive tstatistic (positive asymmetry score) indicates greater activation of the F3 electrode or the left hemisphere of the frontal cortex compared to the right (F4 electrode). As expected no difference was found for the pre-event comparison ( $p>0.05$ ). Post-event analysis found a significant difference between the cereal and milk (spoilage) videos $(\mathrm{p}=0.011$ ); the negative $\mathrm{t}$-statistic presents a greater activation of the F4 electrode (right hemisphere) indicating a withdrawal response to the evented video. No differences were found for the hygiene $(\mathrm{p}=0.392)$ and safety $(\mathrm{p}=0.388)$ concern video sets for the post-event analysis. Additional exploratory statistical approach for EEG data includes a similar analysis to the time series graphs made for AFEA (Figure 5); the cereal and milk video was chosen as an example illustration. Time zero denotes when the event occurred and data for five seconds before and after event occurrence are presented. The blue line represents the change in mean frontal cortex asymmetry score (F4-F3 
electrodes) over time for the control, while the red line represents the evented stimuli. A greater relative $\mathrm{F} 4$ electrode response (positive value) is indicative of a withdrawal response, while a greater relative F3 electrode response (negative value) indicates an approach motivated response. Before the event occurred both videos were approach motivated. Following the event occurrence, the evented video became more withdrawing while the control remained approach oriented.

\section{DISCUSSION}

Significantly lower hedonic scores for all evented videos, compared to the control videos, provides a strong indication that the quality or safety food challenges were observed in the three evented videos. Additional supportive evidence was found from the emotional terminology selection; withdrawal emotions were more frequently chosen for evented videos, while control videos overwhelmingly received greater approach emotion selection. With disgust being the only option if one is repulsed by the stimuli, it should be noted that the emotional terminology options for expressing repulsion and withdrawal are limited. This unequal representation of terms could have unintentionally skewed the results (Chaya, Pacoud, Ng, Fenton \& Hort, 2015; $\mathrm{Ng}$ et al., 2013). However with statistically significant differences in explicit measures between the control and evented videos, it is clear that participants consciously identified the concerns. This also illustrates that the use of the modified CATA emotional terminology ballot, developed for product development and characterizing explicit emotional response to well-liked food products (King and Meiselman, 2010), should be modified further when testing products of unknown quality or when assessing consumer awareness of withdrawal.

The cereal and milk breakfast meal (spoilage) stimuli showed the most promising implicit results to support the explicit measures and thus will be the focus of the discussion. As expected, 
the AFEA time series illustrated withdrawal emotions for the evented video. Disgust and sad (as well as surprised (approach) were the predominant emotions expressed post-event occurrence in the evented video, while neutral was the predominant expression in the control. These findings support previous research on food and facial expression analysis that describe negative facial expressions as more identifiable than positive expressions (Wendin et al., 2009), and positively valanced responses are most often identified as a neutral facial expression (Danner et al., 2014; de Wijk et al., 2012; de Wijk et al., 2014; Wendin et al., 2014; Zeinstra et. al., 2009). Conversely, mean intensity scores of the expressed emotions show both sad and disgust with very small mean intensities (0.090 and 0.073; respectively) in comparison to other emotions such as anger and surprise (0.195 and 0.171 ; respectively).

Time series statistical analysis results were valuable in evaluating the dynamic nature of the emotional responses. Similar time series plots were evaluated for mean difference in emotional intensities between evented and control responses. However, these results were often misleading because of the high variability across participants. High magnitude differences were often not statistically significant. For example, the highest magnitude post-event differences for the safety video occurred for the emotions neutral (control had a higher response) and surprised (evented had a high response) emotions (Figure 5c) compared to any other emotions. These differences, however, were not statistically significant at any point in the time series. The ANOVA using the time-averaged means confirmed this (Table 3). HR response saw a significant decrease $(\mathrm{p}=0.018, \mathrm{t}=-2.481)$ in the post-event analysis for the evented stimuli compared to the control, potentially indicating sad (non-crying) feelings (Kreibig, 2010). Sad was a significant facial expression in the post-event analysis of the spoilage concern stimuli suggesting a relationship to the HR response. Lack of specific emotion identification in HR 
responses does not allow for a clear conclusion, especially without explicit support. For example, disgust was also significantly expressed in the post-event analysis of the AFEA time series analysis, however disgust (contamination) is known to increase HR responses (Kreibig, 2010). The opposing responses provides question of how to determine which emotion/s are more influential in the overall result. Frontal cortex activity further supports the AFEA and HR findings. In the t-test analysis, a significant difference in the frontal EEG asymmetry score $(\mathrm{p}=0.037 ; \mathrm{t}=-2.168)$ presents greater right hemisphere activity for the evented video, which is associated with a withdrawal motivational behavior. The exploratory time series analysis of the EEG data similarly provides supportive evidence; as initially hypothesized, the results indicate approach behavior tendency prior to event occurrence and a switch to withdrawal following the event occurrence. Support is evident across all implicit measures for a withdrawing effect from the spoilage concern. Some additional supportive information was found with the alternative video matches, however less consistency render the need to discuss limitations of the experiment.

Implicit results were subject to three limitations. First, the choice of medium to display the stimuli is a concern. Food is a multi-sensorial experience. Although videos and images are common stimuli types in psychology literature, in a food experience having only the visual may not have been able to elicit the emotional and motivational behavior responses expected. Other senses, such as taste and smell are particularly important in the food experience. Videos were chosen due to laboratory limitations and for control purposes across participants; the videos allowed for all participants to be subject to the same experience. However, it is likely that a combination of sensory aspects of food will elicit a more real response. Secondly, the nature of the stimuli is likely a limitation to the implicit responses. In psychology literature, the stimuli 
used are often on extreme ends of the spectrum. Stimuli aim to produce emotional experiences of complete bliss to graphic revulsion in order to be certain the intended response is elicited. For example, puppies playing in flowers or a gorilla taking a bath are used as positive valanced video stimuli, while videos of amputations or burn victims are negatively valanced stimuli (Davidson et al., 1990). The majority of participants $(82.5 \%)$ liked both the cereal and the milk, however eliciting the same extreme responses to food is nearly impossible because food is generally a positive everyday item. The implicit tools used in this research may not be sensitive enough to detect small differences in consumer response to food contributing to the inconsistent results across meal types. With only a limited number of research studies and a broad range of study conditions and food stimuli on which to estimate person-to-person variability, it is difficult to estimate the normal range of implicit responses. Lastly, the nature of how this type of reseach is collected creates another limitation. Effort was made to try to make the participants confortable during the study, however wearing an EEG cap and HR electrodes is an unuscal situation leading to an inherently uncomfortable condition for most. At this time there is no more natural alternative for this type of study.

Additional inconsistencies between different stimuli requires discussion on experimental design limitations. The setting of the video and the general actions of each stimulus were similar, but no preliminary tests for establishing equal perception of the stimuli attributes such as coloring, brightness, contrast, resolution and size were made (Berkman \& Lieberman, 2009). Internal beta testing had recognized the sausage sandwich breakfast meal's safety concern as most difficult to identify and/or the condition of the pink and raw meat patties may not be condersidered an obstacle for consumption to some. Subsequently, this video was always placed last in video presentation sequence in an effort to ensure adequate attention to the other stimuli as 
there was concern for the conistance of emotional response to the sausage sandwich's concern. As a result, the safety video was always subject to the most participant fatigue, potentially contributing to the inconsistent and minimally significant facial expressions, as well as the lack of significant brain activity findings. Additionally, the beach scene video was used as an effort to return participants to a calm neutral state, howvever it may have had a more positive or approach motivivated effect than expected. Each video was preceeded by this beach scene video and consequently effected each response in the same manner; furture research would benefit from studying proper stimuli for returning participants back to baseline in food research.

Explicit responses provide evidence for participants being able to cognitively identify a concern, but variability in implicit responses suggests further research on the methodology and deeper exploration into more personal and individual preference differences that could have influenced these findings.

The food preference survey provides important information that helps to further explain some of the variability in implicit and explicit emotion responses; external personal factors may have affected the results and provides some direction for future work. A pre-screening task for product users may have helped reduce the variability of results by providing a more cohesive group and remove specific personal preferences (Berkman \& Lieberman, 2009; Giuliani et al., 2014). Consideration of other factors such as past experiences, memories, frequency of consumption/exposure to food, physical or nutritional state, cultural importance and other personal characteristics/preferences, also come into play (Desmet \& Schifferstein, 2008; Jiang et al., 2014). Although the intention of this study was to observe responses to unpleasant food experiences in a general population, screening for specific types of preferences and/or focusing on products food in the market that are designed to create positive food experiences, may allow 
for a clearer understanding of food-related emotional effects to be uncovered (Walsh, Bell, Gallagher, O’Keefe \& Duncan, 2016).

\section{CONCLUSION}

Elucidating the complex nature of emotional response to food stimuli benefits from combining physiological and neurological (implicit) reactions with cognitive (explicit) responses. It is valuable to have knowledge about withdrawal-eliciting attributes of one's product or service for a greater understanding of how to achieve consumer satisfaction. The results of this study indicate great variability among individuals; however they also suggest the potential for the combination of implicit and explicit measures to better understand consumers through approach/withdrawal motivations and emotions. Further research on methodology and validation efforts are needed to advance this body of work in anticipation for its potential use in various food sectors.

\section{ACKNOWLEDGEMENTS}

This project was funded, in part, by ConAgra Foods (Omaha, NE, USA), the Virginia Tech Institute for Creativity, Arts, and Technology, by the Virginia Agricultural Experiment Station (Blacksburg) and the Hatch Program of the National Institute of Food and Agriculture, U.S. Department of Agriculture (Washington, D.C.). 


\section{REFERENCES}

Addisonsoft. (2015). XLSTAT. New York, New York: Addisonsoft.

Ahern, G.L., \& Schwartz, G.E. (1985). Differential lateralization for positive and negative emotion in the human brain: EGG spectral analysis. Neuropsychologia, 23, 745-755.

Doi:10.1016/0028-3932(85)90081.

Alves, N.T., Fukusima, S.S., \& Aznar-Casanova, J.A. (2008). Models of brain asymmetry in emotional processing. Psychology \& Neuroscience, 1(1), 63-66.

Arnade, E.A. (2013). Measuring consumer emotional response to tastes and foods through facial expression analysis. Master's Thesis (Major Advisor: S.E. Duncan), Virginia Tech, Blacksburg.

Arnade, E.A., Duncan, S., Rudd, R., Dunsmore, J., \& O’Keefe, S. 2013. Characterizing consumer emotional response to flavored and unflavored milk through an emotion-based questionnaire. J. Dairy Sci. 96(E-Suppl. 1), 39 (Abstract T108).

Bell, M.A., \& Cuevas, K. (2012). Using EEG to study cognitive development: Issues and practices. Invited manuscript for "Tools of the Trade" series. Journal of Cognition and Development, 13, 281-294.

Berkman, E.T., \& Lieberman, M.D. (2009). Approaching the bad and avoiding the good: Lateral prefrontal cortical asymmetry distinguishes between action and valence. Journal of Cognitive Neuroscience, 22(9), 1970-1979.

Chaya, C., Pacoud, J., Ng, M., Fenton, A., \& Hort, J. (2015). Measuring the emotional response to beer and the relative impact of sensory and packaging cues. Journal of the American Society of Brewing Chemists, 73(1), 49-60.

Coan, J.A, \& Allen, J.J.B. (2003). Frontal EEG Asymmetry and the behavioral activation and inhibition systems. Psychophysiology, 40, 106-114.

Coan, J.A, \& Allen, J.J.B. (2004). Frontal EEG Asymmetry as a moderator and mediator of emotion. Biological Psychology, 67, 7-49.

Crist, C.A., Duncan, S.E., Gallagher, D.L. (2016). Protocol for data collection and analysis applied to automated facial expression analysis technology and temporal analysis for sensory evaluation. J. Visualized Experiments. 114:e54046, epubdoi.10.3791/54046.

Danner, L., Haindl, S., Joechl, M. \& Duerrschmind, K. (2014). Facial expression and autonomous nervous system responses elicited by tasting different juices. Food Research International, 64(2014), 81-90.

Danner, L., Sidorkina, L., Joechl, M. \& Duerrschmind, K. (2013). Make a face! Implicit and Explicit measurement of facial expressions elicited by orange juice using face reading technology. Food Quality and Preference, 32(B), 167-172. 
Davidson, R.J. (2004). What does the prefrontal cortex "do" in affect: perspectives on frontal EEG asymmetry research. Biological Psychology. 67, 219-233.

Davidson, R.J., Ekman, P., Saron, C. D., Senulis, J.A., \& Friesen, W.V. (1990). Approachwithdrawal and cerebral asymmetry: emotional expression and brain physiology I. Journal of Personality and Social Psychology, 58(2), 330-341.

Davidson, R.J., \& Irwin, W. (1999). The functional neuroanatomy of emotion and affective style. Trends in Cognitive Sciences, 3(1), 11-21.

de Wijk, R.A, He, W., Mensink, M.G.J., Verhoeven, R.H.G., \& de Graaf, C. (2014). ANS Responses and facial expressions differentiate between the taste of commercial breakfast drinks. PLoS ONE, 9(4) e93823. doi:10.1371/journal.pone.0093823.

de Wijk, R.A., Kooijman, V., Verhoeven, R.H.G, Holthuysen, N.T.E, \& de Graaf, C. (2012). Autonomic nervous system responses on and facial expressions to the sight, smell, and taste of liked and disliked foods. Food Quality and Preference, 26 (2), 130-137.

Desmet, P.M.A., \& Hekkert, P. (2009). Special issue editorial: Design \& emotion. International Journal of Design, 3(2), 1-6.

Desmet, P.M.A, \& Schifferstein, H.N.J., (2008). Sources of positive and negative emotions in food experience. Appetite. 50, 290-301.

Diaz, A., \& Bell, M.A. (2012). Frontal EEG asymmetry and fear reactivity in different contexts at 10 months. Developmental Psychobiology, 54, 536-545. Doi: 10.1002/dev.20612.

Ekman, P., Friesen, W.V., \& Davidson, R.J. (1990). The duchenne smile: emotional expression and brain physiology II. Journal of Personality and Social Psychology, 58. (2). 342-353.

Ekman, P., Friesen, W. V., O’Sullivan, M., Chan, A., Diacoyanni-Tarlatzis, I., Heider, K., Krause, R., LeCompte, W. A., Pitcairn, T., Ricci-Bitti, P. E., Scherer, K., Tomita, M., \& Tzavaras, A. (1987). Universals and cultural differences in the judgments of facial expressions of emotion. Journal of Personality and Social Psychology, 53 (4), 712-717.

Fernandez, C., Pascual, J.C., Soler, J., Elices, M., Portella, M.J., \& Fernandez-Abascal, E. (2012). Physiological responses induced by emotion-eliciting films. Applied Psychophysiology and Biofeedback, 77, 73-79.

Fox, N.A., Kirwan, M., \& Reeb-Sutherland, B. (2012). Measuring the physiology of emotion and emotion regulation-timing is everything. Monographs of the Society for Research in Child Development, 77(2), 98-108. Doi: 10.1111/j.1540-5834.2011.00668.x.

Garcia Burgos, D., \& Zamora, M.C. (2015). Exploring the hedonic and incentive properties in preferences for bitter foods via self-reports, facial expressions and instrumental behaviours. Food Quality and Preference, 39, 73-81.

García Burgos, D., \& Zamora, M.C. (2013). Facial affective reactions to bitter-tasting foods and body mass index in adults. Appetite, 71(1), 178-186. 
Giuliani, N.R., Mann, T., Tomiyama, A.J., \& Berkman, E.T. (2014). Neural systems underlying the reappraisal of personally craved foods. Journal of Cognitive Neuroscience, 26(7). 1390-1402.

Gutjar, S., de Graaf, C., Kooijman, V., de Wijk, R.A., Nys, A., ter Horst, G.J., \& Jager, G. (2015). The role of emotions in food choice and liking. Food Research International, 76, 216223.

Harmon-Jones, E., Gable, P.A., \& Peterson, C.K. (2010). The role of asymmetric frontal cortical activity in emotion-related phenomena: A review and update. Biological Psychology, 84. 451462.

He, W., Boesveldt, S., de Graaf, C., \& de Wijk, R.A., (2014). Dynamics of autonomic nervous system responses and facial expressions to odors. Frontiers in Psychology, 5 (110), 1-8.

He, W., Boesveldt, S., de Graaf, C., \& de Wijk, R.A., (2016). The relation between continuous and discrete emotional responses to food odors with facial expressions and non-verbal reports. Food Quality and Preference, 48, 130-137.

IBM Corporation (2014). IBM SPSS Statistics. Armonk, New York: IBM Corporation.

Jiang, Y., King, J., \& Prinyawiwatkul, W. (2014). A review of measurement and relationships between food, eating behavior and emotion. Trends in Food Science \& Technology, 36, 15-28.

JMP, Statistical Analysis Software (SAS) Version 9.2, SAS Institute, Cary, NC.

King, S. C., \& Meiselman, H. L. (2010). Development of a method to measure consumer emotions associated with foods. Food Quality and Preference, 21(2), 168-177. doi:10.1016/j.foodqual.2009.02.005

King, S. C., Meiselman, H. L., \& Carr, B. T. (2010). Measuring emotions associated with foods in consumer testing. Food Quality and Preference, 21(8), 1114-1116.

doi:10.1016/j.foodqual.2010.08.004

Kring, A.M., \& Sloan, D.M. (2007). The Facial Expression Coding System (FACES):

Development, validation, and utility. Psychological Assessment, 19(2), 210-224.

Kreibig, S.D. (2010). Automatic nervous system activity in emotion: A review. Biological Psychology, 84, 394-421.

Kubberod, E., Ueland, O., Dingstad, G.I., Risvik, E., \& Henjesand, I.J. (2008). The effect of animality in the consumption experience - A potential for disgust. Journal of Food Products Marketing, 14(3), 103-124.

Lassoued, R. \& Hobbs, J.E. (2015). Consumer confidence in credence attributes: The role of brand trust. Food Policy, 52, 99-107. 
Leitch, K.A., Duncan, S.E. O'Keefe S.F., Rudd, R., \& Gallagher, D.A. (2015). Characterizing consumer emotional response to sweeteners using an emotion terminology questionnaire and facial expression analysis. Food Research International, 76, 283-292.

Loijens, L., \& Krips O. (2012). FaceReader Methodology [White Paper]. Retrieved from http://www.noldus.com/webfm_send/618

Meiselman, H. (2015). A review of the current state of emotion reserch in product development. Food Research International, 76, 192-199.

Microsoft. (2013). Microsoft Excel Windows. Redmond, Washington: Microsoft.

Ng, M., Chaya, C., \& Hort, J. (2013). Beyond liking: Comparing the measurement of emotional response using EsSense Profile and consumer defined check-all-that-apply methodologies. Food Quality and Preference, 28. 193-205.

Noldus Information Technology (2012). FaceReader $5^{T M}$ reference manual. Noldus Information Technology, Wageningen, The Netherlands. Available from http://www.noldus.com.

Olsen, N. V., Røssvoll, E., Langsrud, S., \& Scholderer, J. (2014). Hamburger hazards and emotions. Appetite; Eating and Drinking, 78C, 95-101.

Pizzagalli, D. A. (2007). Electroencephalography and high-density electrophysiological source localization. In J. T. Cacioppo, L. G. Tassinary, \& G. G. Berntson (Eds.), Handbook of Psychophysiology (3rd ed., pp. 56-84). Cambridge, UK: Cambridge University Press.

R Core Team. (2013). R: A language and environment for statistical computing. R Foundation for Statistical Computing, Vienna, Austria. Retrieved from http://www.R-project.org/.

Røssvoll E., Sørheim O., Heir E., Møretrø T., Olsen N.V., \& Langsrud, S. (2013). Consumer preferences, internal color and reduction of shigatoxigenic Escherichia coli in cooked hamburgers. Meat Science, 96, 695-703.

Rozin, P. (1996). Towards a psychology of food and eating: From motivation to module to model to marker, morality, meaning, and metaphor. Current Directions in Psychology Science, 5 (1), 18-24.

Rozin, P. (1999). Food is fundamental, fun, frightening, and far-reaching. Social Research, 66(1), 9-30.

Rozin, P. (2007). Disgust. In R. F. Baumeister \& K. D. Vohs (Eds.). Encyclopedia of Social Psychology, 255-257. Thousand Oaks, CA: Sage.

Rozin, P., \& Fallon, A.E. (1987). A perspective on disgust. Psychological Review, 94, 23-41.

Scherer, K.R. (2000). Emotion. In M. Hewstone \& W. Stroebe (Eds.). Introduction to Social Psychology: A European perspective (3 ${ }^{\text {rd }}$ ed., pp. 151-191). Oxford: Blackwell. 
Siep, N., Roefs, A., Roebroeck, A., Havermans, R., Bonte, M., \& Jansen, A. (2012). Fighting food temptations: The modulating effects of short-term cognitive reappraisal, suppression and up-regulation on mesocorticolimbic activity related to appetitive motivation. NeuroImage, 60, 213-220.

Silva, J.R., Pizzagalli, D.A., Larson, C.L., Jackson, D.C., \& Davidson, R.J. (2002). Frontal brain asymmetry in restrained eaters. Journal of Abnormal Psychology, 111(4). 676-681.

Shimp, T.A., \& Stuart, E.W. (2004). The role of disgust as an emotional mediator of advertising effects. Journal of Advertising, 3(1), 43-53.

Walsh, A.M., Duncan, S.E., Potts, H., \& Gallagher, D. (2015). Characterization of implicit and explicit emotions as related to acceptability of light induced oxidation flavor in milk. Food Research International; Food and Emotions, 76, 293-300.

Walsh, A.M., Bell, M.A., Gallagher, D., O’Keefe, S., \& Duncan, S.E. (2016). Integrating implicit and explicit emotional assessment of pleasurable meal experiences. The Society of Sensory Professionals' Technical and Professional Conference. (Abstract). October 26-28, Atlanta, GA.

Wardy, W., Sae-Eaw, A., Sriwattana, S., No, H.K., \& Prinyawiwatkul, W. (2015). Assessing consumer emotional responses in the presence and absence of critical quality attributes: A case study with chicken eggs. Journal of Food Science, 80(7), S1574- S1582.

Wendin, K., Bredie, W.L.P., \& Tan, H.S.G. (2014). A comparative study on facially expressed emotions in response to basic tastes. Chemosensory Perception, 7, 1-9.

Zeinstra, G.G, Koelen, M., Colindres, D., Kok, F.J., \& de Graaf, C. (2009). Facial expressions in school-aged children are a good indicator of "dislikes," but not of "likes." Food Quality and Preference, 20, 620-624. 


\section{List of Figures:}

Figure 1: Single scheme of video presentation sequence.

Figure 2: Acceptability scores (mean \pm s.d.) for control and evented breakfast meals $(n=40$; $1=$ "dislike extremely"; $7=$ "like extremely"); ${ }^{a, b, c, d}$ bars with different superscripts significantly differ in mean score $(p<0.05)$.

Figure 3: Emotional term selection for control and evented breakfast meals ( $n=40)$; $a$.) Cereal and milk, b.) Pancakes and fruit, c.) Sausage sandwich breakfast meals.

Figure 4: Time series comparison of the six basic emotions expressed and a neutral state between the three sets of control and evented breakfast meals; Time series indicating the presence and directionality of statistically significantly greater emotion expression intensities from sequential paired nonparametric Wilcoxon tests $(\alpha=0.025 ; n=40) ;$ a.) spoilage quality (cereal and milk), b.) hygiene quality (pancakes and fruit), c.) safety (sausage sandwich).

Figure 5: Time series graph of frontal cortex asymmetries (F4-F3 electrodes) of the evented cereal and milk (red) and the control cereal and milk (blue) videos $(n=40)$; for 5 seconds pre and 5 seconds post event. 


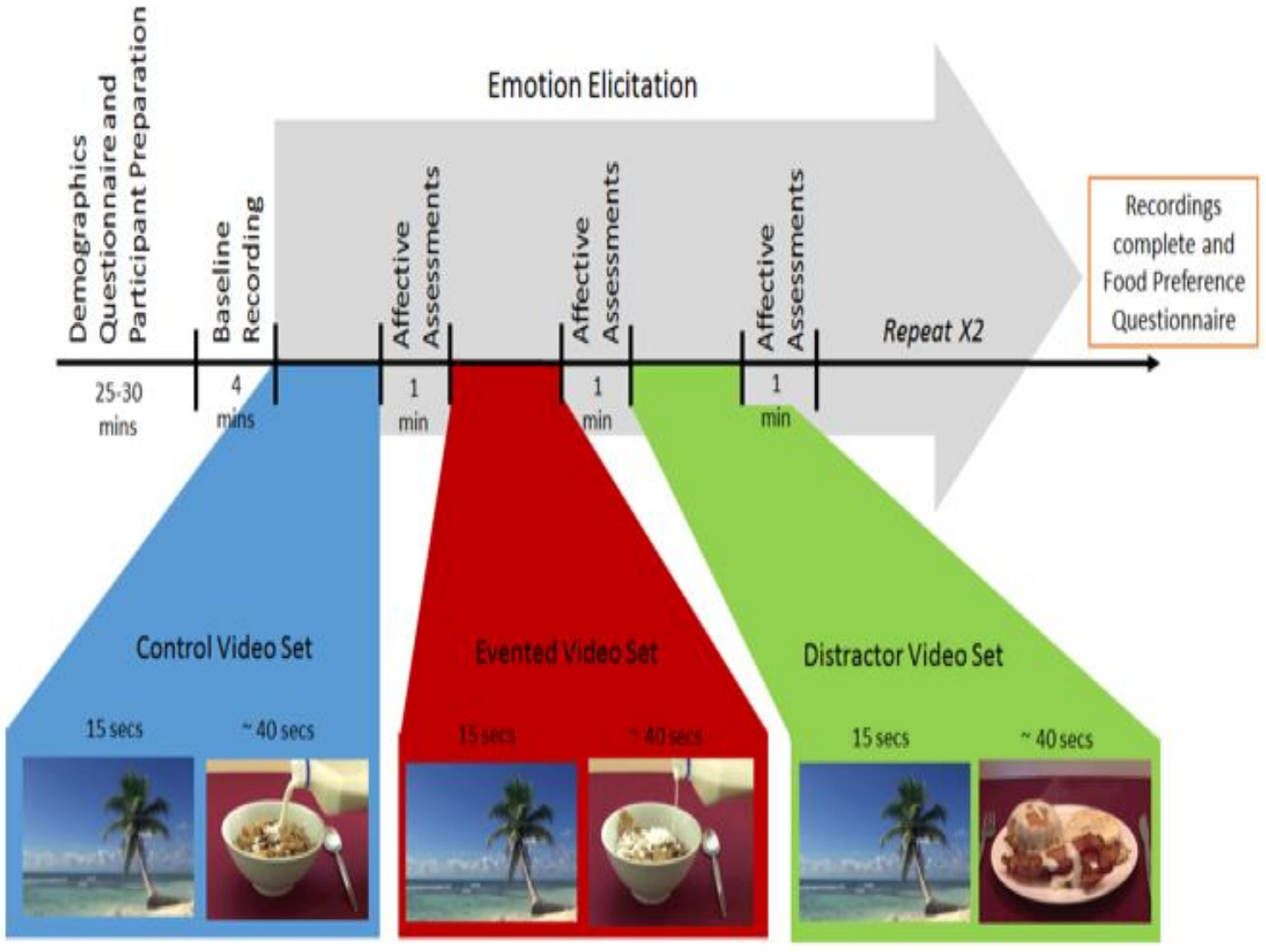




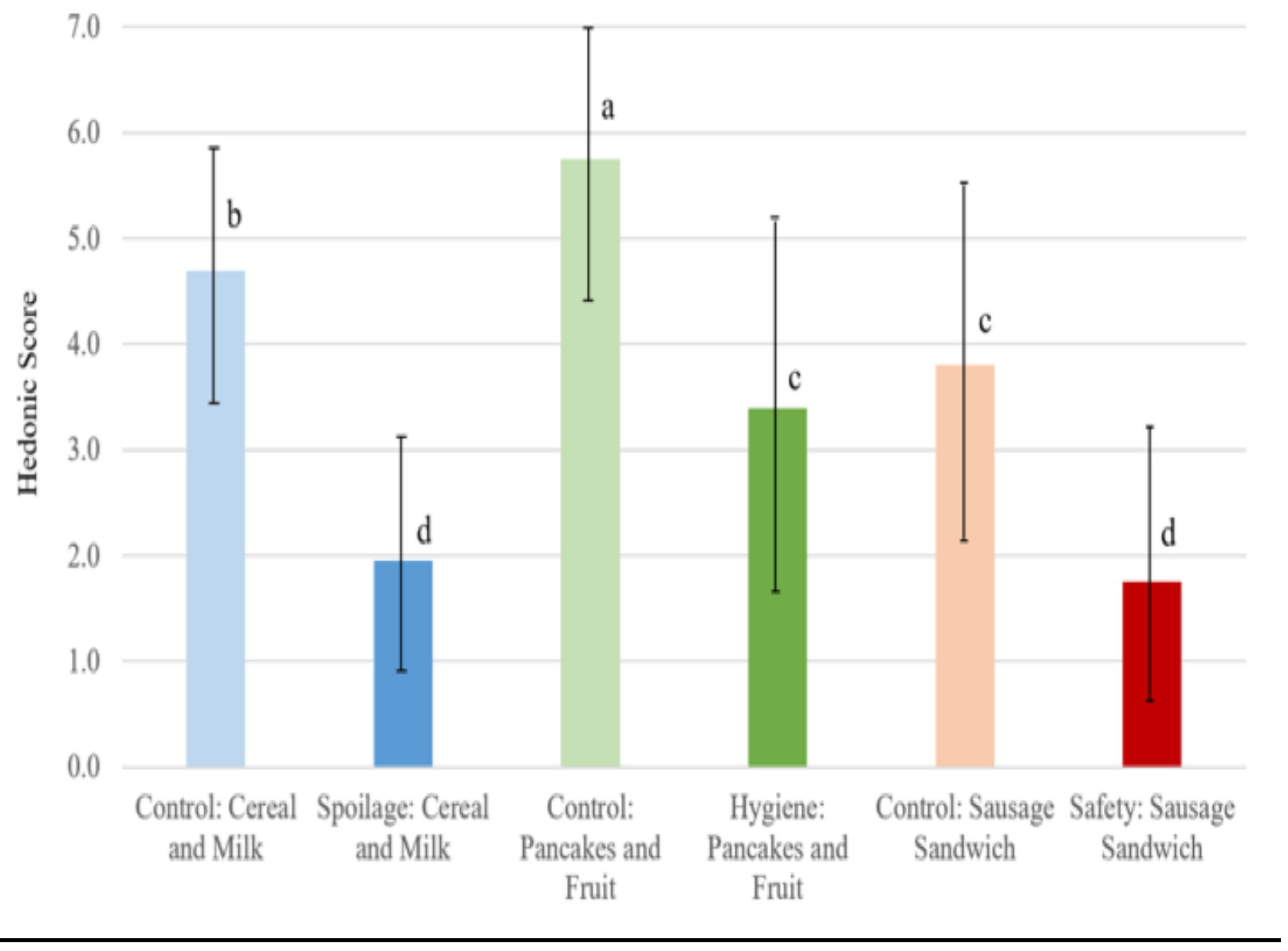


a) Spoilage Quality

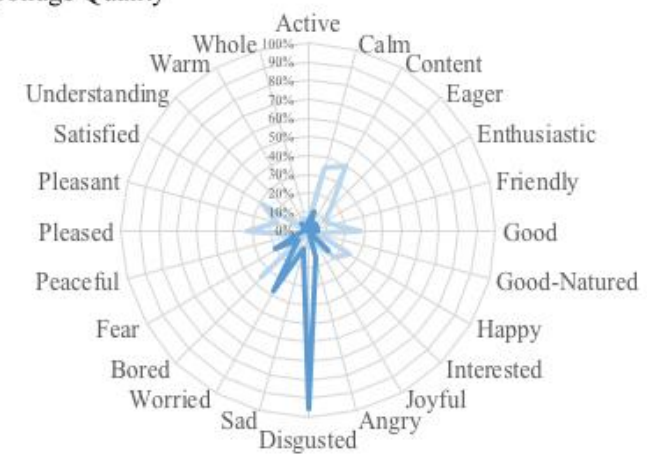

Control: Cereal and Milk

-Spoilage: Cereal and Milk

b) Hygiene Quality

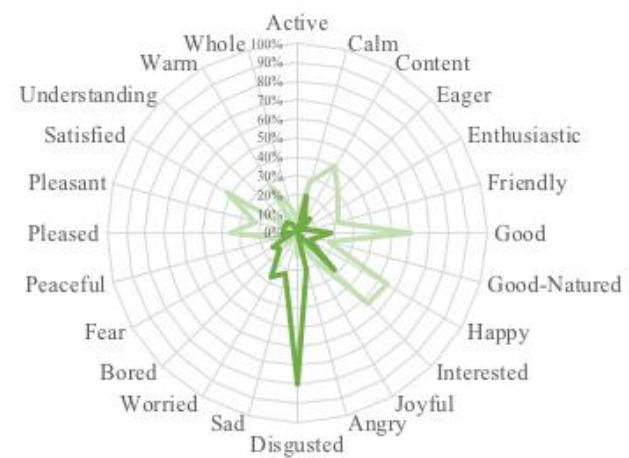

Control: Pancakes and Fruit

Hygiene: Pancakes and Fruit

\section{c) Safety}

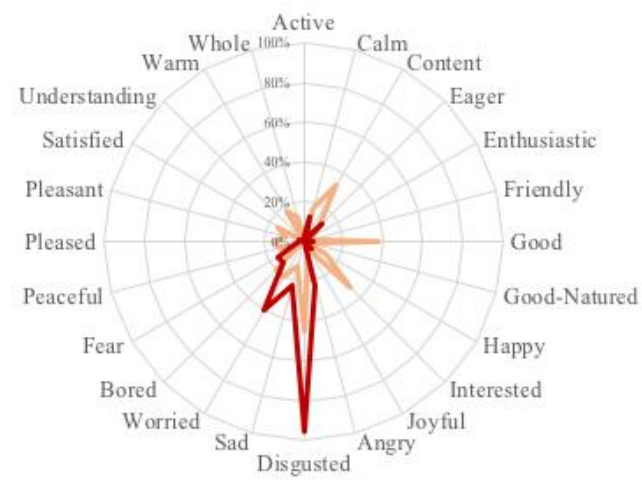

Control: Sausage Sandwich

- Safety: Sausage Sandwich 
a) Spoilage Quality

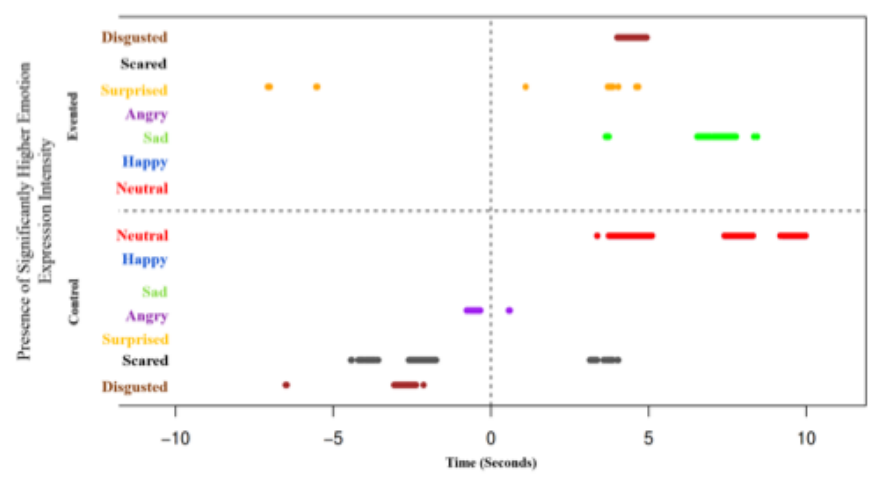

b) Hygiene Quality

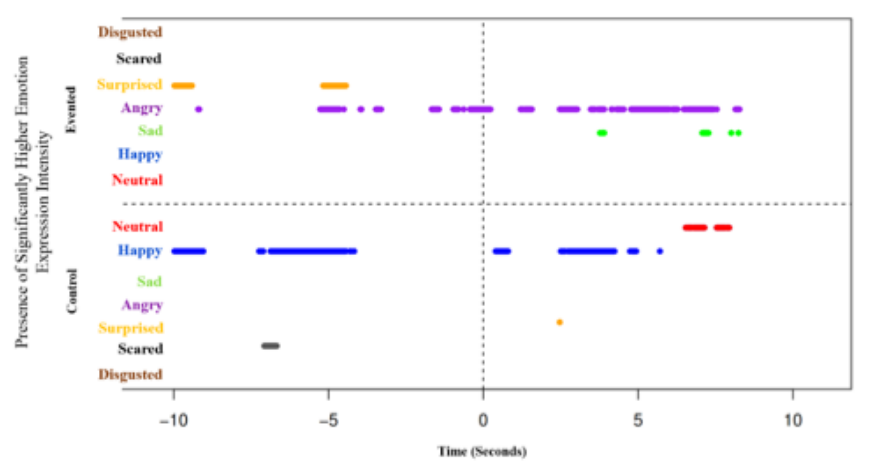

c) Safety

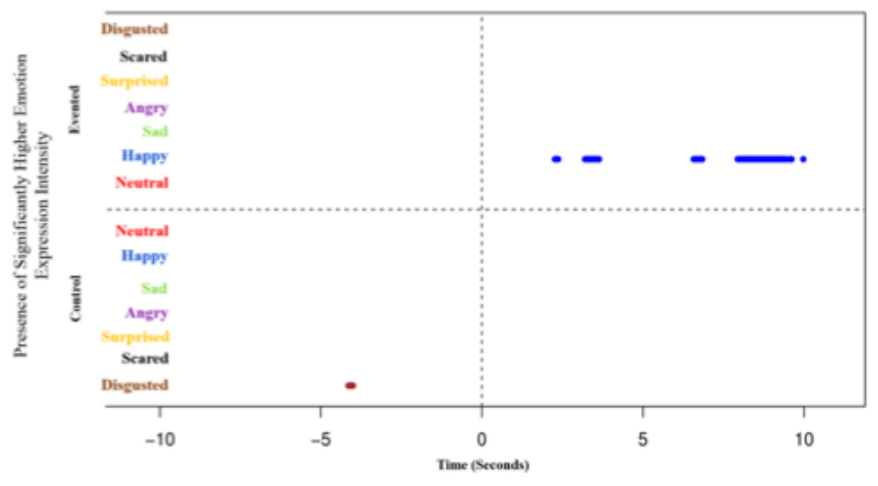




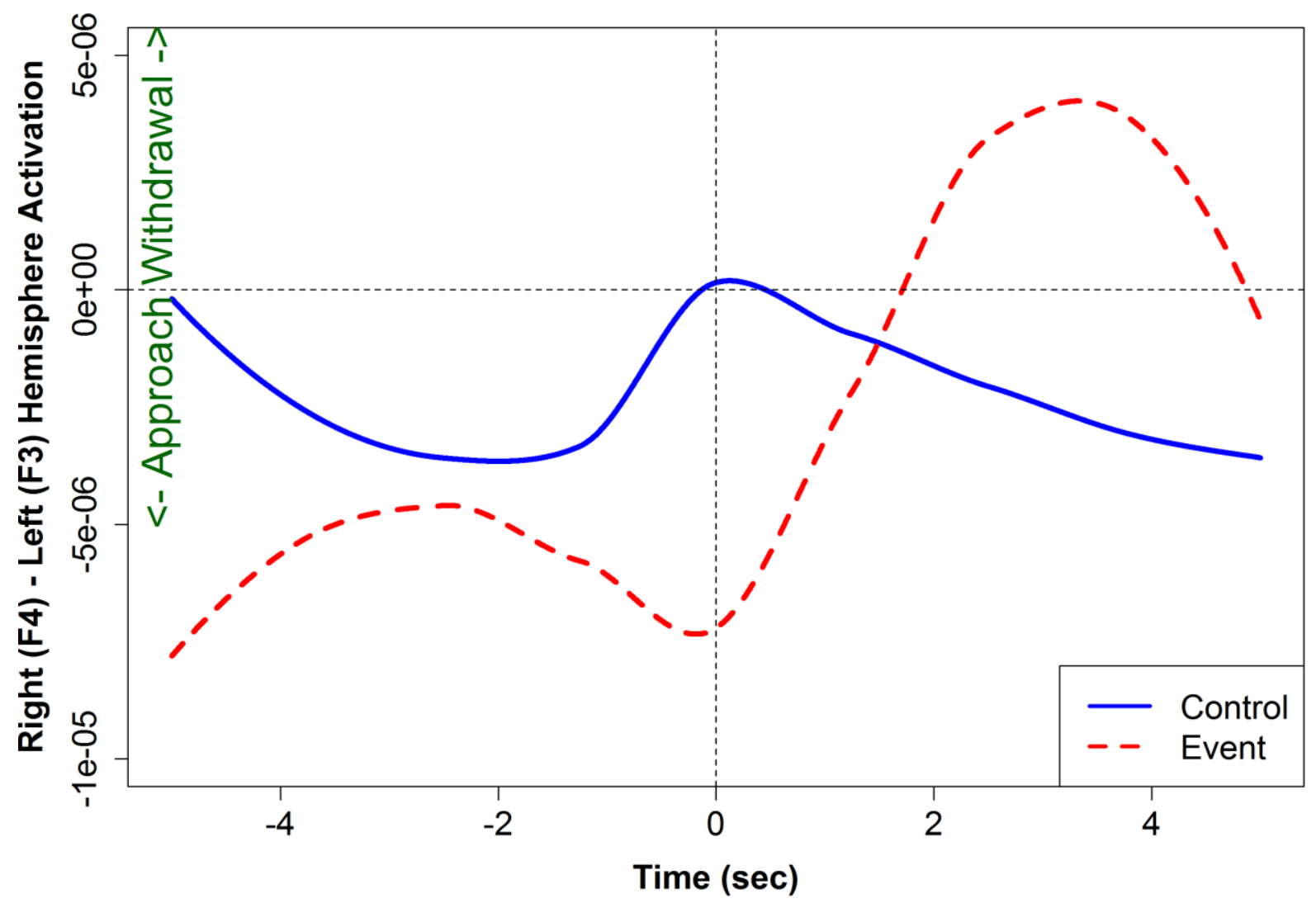


Table 1: Image representation of control breakfast meal and distractor videos, and a description of the corresponding "evented" videos presented.

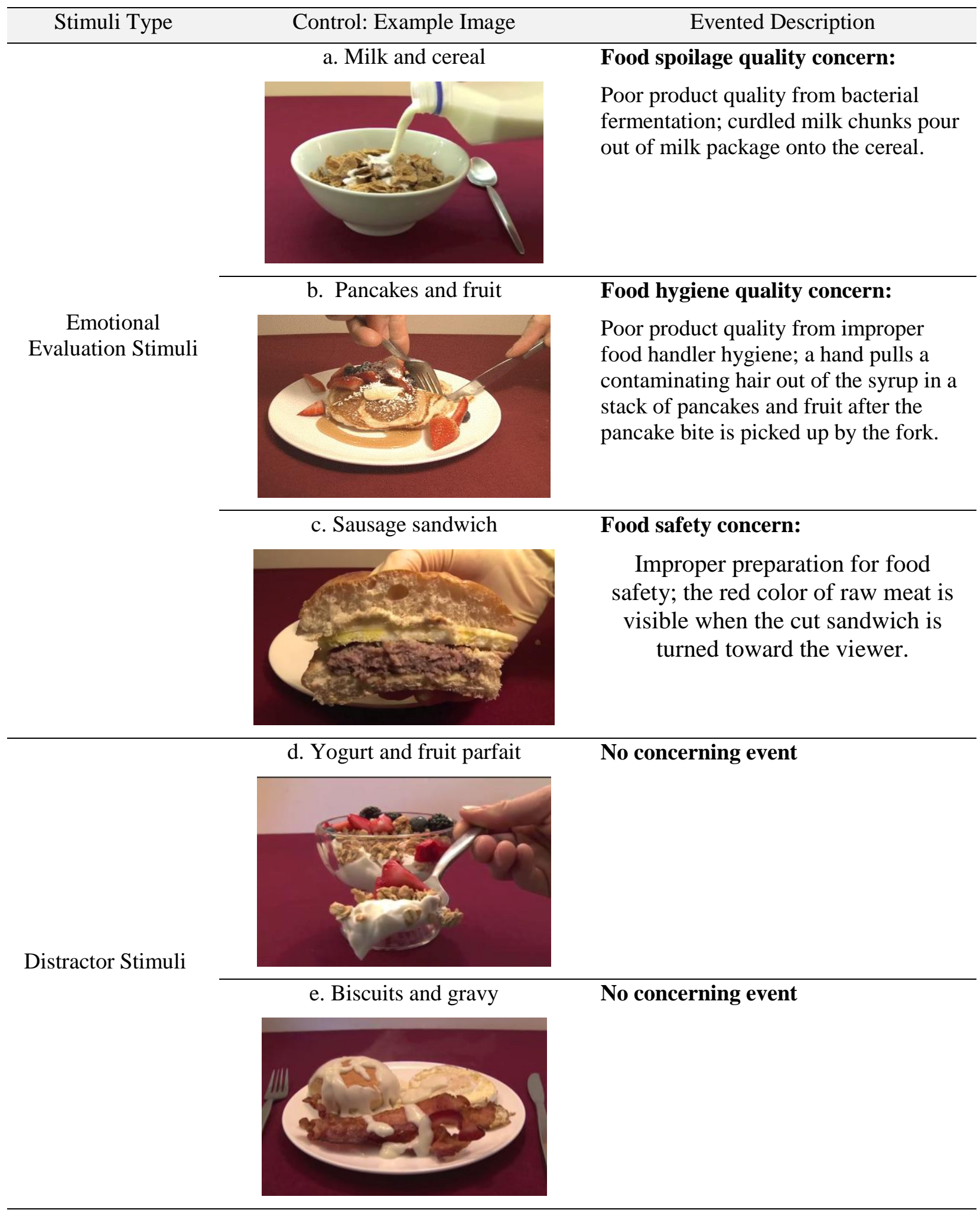




\begin{tabular}{ll}
\hline f. Beach scene & $\begin{array}{l}\text { No concerning event } \\
\text { Palm tree on a beach with waves } \\
\text { ebbing. }\end{array}$ \\
\end{tabular}


Table 2: Statistical summary for acceptability scores for breakfast meals (matched control and evented videos) illustrating quality and safety differences.

\begin{tabular}{|c|c|c|c|c|c|c|}
\hline \multirow[b]{2}{*}{ Video } & \multirow{2}{*}{$\begin{array}{c}\text { Event } \\
\text { Category }\end{array}$} & \multirow[b]{2}{*}{ M } & \multirow[b]{2}{*}{ SD } & \multicolumn{2}{|c|}{$95 \% \mathrm{CI}$} & \multirow[b]{2}{*}{ Median } \\
\hline & & & & Lower & Upper & \\
\hline \multirow{2}{*}{ Cereal and Milk } & Control & $4.7^{\mathrm{b}}$ & 1.24 & 4.30 & 5.10 & 5.0 \\
\hline & Spoilage & $2.0^{\mathrm{d}}$ & 1.15 & 1.58 & 2.32 & 2.0 \\
\hline \multirow{2}{*}{ Pancakes and Fruit } & Control & $5.8^{\mathrm{a}}$ & 1.34 & 5.32 & 6.18 & 6.0 \\
\hline & Hygiene & $3.4^{\mathrm{c}}$ & 1.72 & 2.85 & 3.95 & 3.0 \\
\hline \multirow{2}{*}{ Sausage Sandwich } & Control & $3.8^{\mathrm{c}}$ & 1.73 & 3.25 & 4.35 & 4.0 \\
\hline & Safety & $1.8^{\mathrm{d}}$ & 1.30 & 1.34 & 2.16 & 1.0 \\
\hline
\end{tabular}

a, b, c, d Means $(n=40)$ with different superscripts are significantly different $(\mathrm{p}<0.05)$. 
Table 3: Mean intensities ( \pm s.d.) post-event occurrence of expressed emotions identified by automated facial expression analysis and multiple comparisons within emotion and across video stimuli (five seconds; $n=40, p<0.05$ ).

\begin{tabular}{|c|c|c|c|c|c|c|c|c|c|c|c|c|c|c|c|}
\hline \multicolumn{16}{|c|}{5 Sec Post Event: } \\
\hline \multirow{2}{*}{$\begin{array}{c}\text { Food } \\
\text { Stimuli }\end{array}$} & \multirow[b]{2}{*}{ Event } & \multicolumn{2}{|c|}{ Neutral } & \multicolumn{2}{|c|}{ Happy } & \multicolumn{2}{|c|}{$\mathrm{Sad}$} & \multicolumn{2}{|c|}{ Anger } & \multicolumn{2}{|c|}{ Surprise } & \multicolumn{2}{|c|}{ Scared } & \multicolumn{2}{|c|}{ Disgust } \\
\hline & & M & SD & M & SD & M & SD & $\mathrm{M}$ & SD & M & SD & M & SD & $\mathrm{M}$ & SD \\
\hline \multirow{2}{*}{$\begin{array}{l}\text { Cereal and } \\
\text { Milk }\end{array}$} & Control & $0.462^{\mathrm{a}}$ & 0.314 & $0.007^{\mathrm{c}}$ & 0.029 & $0.048^{\mathrm{c}}$ & 0.164 & $0.216^{\mathrm{b}}$ & 0.350 & $0.132^{\mathrm{bc}}$ & 0.300 & $0.005^{\mathrm{c}}$ & 0.020 & $0.033^{\mathrm{c}}$ & 0.093 \\
\hline & Spoilage & $0.394^{\mathrm{a}}$ & 0.331 & $0.027^{\mathrm{cd}}$ & 0.116 & $0.090^{\text {bcd }}$ & 0.230 & $0.195^{\mathrm{b}}$ & 0.326 & $0.171^{\mathrm{bc}}$ & 0.347 & $0.006^{\mathrm{d}}$ & 0.034 & $0.073^{\mathrm{bcd}}$ & 0.207 \\
\hline \multirow{2}{*}{$\begin{array}{l}\text { Pancakes } \\
\text { and Fruit }\end{array}$} & Control & $0.464^{\mathrm{a}}$ & 0.288 & $0.037^{\mathrm{b}}$ & 0.121 & $0.042^{\mathrm{b}}$ & 0.148 & $0.159^{b}$ & 0.297 & $0.124^{\mathrm{b}}$ & 0.278 & $0.032^{\mathrm{b}}$ & 0.107 & $0.031^{\mathrm{b}}$ & 0.090 \\
\hline & Hygiene & $0.423^{\mathrm{a}}$ & 0.300 & $0.032^{\mathrm{c}}$ & 0.134 & $0.048^{\mathrm{c}}$ & 0.140 & $0.215^{\mathrm{b}}$ & 0.345 & $0.115^{\mathrm{bc}}$ & 0.271 & $0.023^{\mathrm{c}}$ & 0.082 & $0.063^{\mathrm{c}}$ & 0.186 \\
\hline \multirow{2}{*}{$\begin{array}{c}\text { Sausage } \\
\text { Sandwich }\end{array}$} & Control & $0.453^{\mathrm{a}}$ & 0.317 & $0.031^{\mathrm{c}}$ & 0.133 & $0.079^{\mathrm{bc}}$ & 0.214 & $0.203^{\mathrm{b}}$ & 0.330 & $0.130^{\mathrm{bc}}$ & 0.285 & $0.008^{\mathrm{c}}$ & 0.045 & $0.031^{\mathrm{c}}$ & 0.098 \\
\hline & Safety & $0.394^{\mathrm{a}}$ & 0.299 & $0.034^{\mathrm{c}}$ & 0.114 & $0.056^{\mathrm{c}}$ & 0.141 & $0.210^{\mathrm{b}}$ & 0.334 & $0.169^{\mathrm{bc}}$ & 0.332 & $0.026^{\mathrm{c}}$ & 0.119 & $0.048^{\mathrm{c}}$ & 0.132 \\
\hline
\end{tabular}

*Means within each emotion (column) had no significant differences ( $\mathrm{p}>0.05)$.

a, b, c Means within each event (row) with different superscripts are significantly different $(\mathrm{p}<0.05)$. 
Table 4: Mean intensities ( \pm s.d.) pre-event occurrence of expressed emotions identified by automated facial expression analysis and multiple comparisons within emotion and across video stimuli (five seconds; $\mathrm{n}=40, \mathrm{p}<0.05$ ).

\begin{tabular}{|c|c|c|c|c|c|c|c|c|c|c|c|c|c|c|c|}
\hline \multicolumn{16}{|c|}{5 Sec Pre Event: } \\
\hline \multirow{2}{*}{$\begin{array}{c}\text { Food } \\
\text { Stimuli }\end{array}$} & \multirow[b]{2}{*}{ Event } & \multicolumn{2}{|c|}{ Neutral } & \multicolumn{2}{|c|}{ Нарpy } & \multicolumn{2}{|c|}{$\mathrm{Sad}$} & \multicolumn{2}{|c|}{ Anger } & \multicolumn{2}{|c|}{ Surprise } & \multicolumn{2}{|c|}{ Scared } & \multicolumn{2}{|c|}{ Disgust } \\
\hline & & $\mathrm{M}$ & SD & $\mathrm{M}$ & SD & $M$ & SD & $\mathrm{M}$ & SD & $\mathrm{M}$ & SD & $M$ & SD & $M$ & SD \\
\hline \multirow{2}{*}{$\begin{array}{l}\text { Cereal and } \\
\text { Milk }\end{array}$} & Control & $0.459^{\mathrm{a}}$ & 0.316 & $0.013^{\mathrm{c}}$ & 0.049 & $0.052^{\mathrm{c}}$ & 0.169 & $0.214^{\mathrm{b}}$ & 0.357 & $0.130^{\mathrm{bc}}$ & 0.289 & $0.012^{\mathrm{c}}$ & 0.060 & $0.039^{c}$ & 0.120 \\
\hline & Spoilage & $0.465^{\mathrm{a}}$ & 0.336 & $0.009^{c}$ & 0.035 & $0.061^{\mathrm{bc}}$ & 0.180 & $0.178^{\mathrm{b}}$ & 0.306 & $0.194^{\mathrm{b}}$ & 0.362 & $0.013^{\mathrm{c}}$ & 0.058 & $0.032^{\mathrm{c}}$ & 0.111 \\
\hline \multirow{2}{*}{$\begin{array}{l}\text { Pancakes } \\
\text { and Fruit }\end{array}$} & Control & $0.482^{\mathrm{a}}$ & 0.278 & $0.032^{\mathrm{bc}}$ & 0.118 & $0.038^{\mathrm{bc}}$ & 0.118 & $0.159^{\mathrm{b}}$ & 0.297 & $0.119^{\mathrm{bc}}$ & 0.268 & $0.028^{\mathrm{c}}$ & 0.083 & $0.030^{\mathrm{bc}}$ & 0.079 \\
\hline & Hygiene & $0.470^{\mathrm{a}}$ & 0.316 & $0.007^{\mathrm{c}}$ & 0.047 & $0.039^{c}$ & 0.123 & $0.212^{\mathrm{b}}$ & 0.341 & $0.141^{\mathrm{bc}}$ & 0.293 & $0.016^{\mathrm{c}}$ & 0.064 & $0.048^{\mathrm{c}}$ & 0.159 \\
\hline \multirow{2}{*}{$\begin{array}{c}\text { Sausage } \\
\text { Sandwich }\end{array}$} & Control & $0.452^{\mathrm{a}}$ & 0.307 & $0.031^{\mathrm{c}}$ & 0.132 & $0.066^{\mathrm{bc}}$ & 0.197 & $0.205^{\mathrm{b}}$ & 0.328 & $0.130^{\mathrm{bc}}$ & 0.282 & $0.008^{\mathrm{c}}$ & 0.041 & $0.044^{\mathrm{bc}}$ & 0.116 \\
\hline & Safety & $0.421^{\mathrm{a}}$ & 0.305 & $0.011^{\mathrm{d}}$ & 0.061 & $0.036^{\mathrm{cd}}$ & 0.120 & $0.235^{\mathrm{b}}$ & 0.338 & $0.163^{\mathrm{bc}}$ & 0.324 & $0.022^{\mathrm{cd}}$ & 0.100 & $0.023^{\text {cd }}$ & 0.066 \\
\hline
\end{tabular}

*Means within each emotion (column) had no significant differences ( $\mathrm{p}>0.05$ ).

a, b, c Means within each event (row) with different superscripts are significantly different $(\mathrm{p}<0.05)$. 
Table 5: Student's t-test comparison of mean heart rate (HR) between control and evented videos for five seconds pre- and post-event ( $n=40, \alpha=0.05)$.

\begin{tabular}{|c|c|c|c|c|c|c|c|c|c|c|}
\hline \multirow[b]{2}{*}{ HR } & \multirow[b]{2}{*}{$\begin{array}{c}\text { Food } \\
\text { Concern }\end{array}$} & \multirow[b]{2}{*}{ Event } & \multicolumn{2}{|c|}{ Control } & \multicolumn{2}{|c|}{ Evented } & \multirow[b]{2}{*}{$\begin{array}{l}\text { Mean } \\
\text { Diff. }\end{array}$} & \multirow[b]{2}{*}{ SD } & \multirow[b]{2}{*}{$\mathrm{t}$} & \multirow[b]{2}{*}{$\mathrm{p}$} \\
\hline & & & $\begin{array}{c}\mathrm{M} \\
(\mathrm{bpm})\end{array}$ & SD & $\begin{array}{c}\mathrm{M} \\
(\mathrm{bpm})\end{array}$ & SD & & & & \\
\hline \multirow{3}{*}{$\begin{array}{c}\text { Five sec pre- } \\
\text { event }\end{array}$} & Spoilage & Cereal and Milk & 73.172 & 10.349 & 74.063 & 10.773 & 0.891 & 5.624 & 1.002 & 0.322 \\
\hline & Hygiene & Pancakes and Fruit & 72.114 & 11.223 & 73.263 & 11.401 & 1.148 & 4.536 & 1.601 & 0.117 \\
\hline & Safety & Sausage Sandwich & 74.646 & 11.034 & 74.992 & 11.186 & 0.346 & 4.465 & 0.491 & 0.626 \\
\hline \multirow{3}{*}{$\begin{array}{c}\text { Five sec } \\
\text { post-event }\end{array}$} & Spoilage & Cereal and Milk & 73.680 & 10.906 & 71.657 & 10.756 & -2.023 & 5.158 & -2.481 & 0.018 \\
\hline & Hygiene & Pancakes and Fruit & 71.282 & 11.082 & 72.593 & 10.820 & 1.311 & 3.927 & 2.111 & 0.041 \\
\hline & Safety & Sausage Sandwich & 71.914 & 11.227 & 73.651 & 10.963 & 1.736 & 4.421 & 2.484 & 0.017 \\
\hline
\end{tabular}


Table 6: Student's t-test comparison of mean frontal cortex asymmetry scores (F4-F3) between control and evented videos for pre- and post-event $(\alpha=0.05)$.

\begin{tabular}{|c|c|c|c|c|c|c|c|c|c|c|c|}
\hline \multirow{2}{*}{$\begin{array}{c}\text { Frontal Cortex } \\
\text { Asymmetry } \\
\text { Scores: F4 - F3 }\end{array}$} & \multirow{2}{*}{$\begin{array}{c}\text { Food } \\
\text { Concern }\end{array}$} & \multirow[b]{2}{*}{ Event } & \multicolumn{2}{|c|}{ Control } & \multicolumn{2}{|c|}{ Evented } & \multirow{2}{*}{$\begin{array}{l}\text { Mean } \\
\text { Diff. }\end{array}$} & \multirow[b]{2}{*}{ SD } & \multirow[b]{2}{*}{$\mathrm{n}$} & \multirow[b]{2}{*}{$\mathrm{t}$} & \multirow[b]{2}{*}{$\mathrm{p}$} \\
\hline & & & M & $\mathrm{SD}$ & M & $\mathrm{SD}$ & & & & & \\
\hline \multirow{3}{*}{$\begin{array}{l}\text { Five sec } \\
\text { pre-event }\end{array}$} & Spoilage & Cereal and Milk & 0.041 & 0.416 & 0.031 & 0.380 & -0.009 & 0.523 & 38 & -0.110 & 0.913 \\
\hline & Hygiene & Pancakes and Fruit & 0.128 & 0.073 & -0.015 & 0.375 & -0.143 & 0.079 & 39 & -1.820 & 0.077 \\
\hline & Safety & Sausage Sandwich & 0.033 & 0.428 & 0.015 & 0.466 & -0.018 & 0.094 & 37 & -0.19 & 0.850 \\
\hline \multirow{3}{*}{$\begin{array}{c}\text { Five sec } \\
\text { post-event }\end{array}$} & Spoilage & Cereal and Milk & 0.075 & 0.414 & -0.130 & 0.342 & -0.205 & 0.473 & 38 & -2.665 & 0.011 \\
\hline & Hygiene & Pancakes and Fruit & 0.073 & 0.429 & 0.013 & 0.055 & -0.060 & 0.437 & 40 & -0.865 & 0.392 \\
\hline & Safety & Sausage Sandwich & 0.153 & 0.628 & 0.058 & 0.388 & -0.095 & 0.676 & 40 & -0.873 & 0.388 \\
\hline
\end{tabular}

